\title{
A Study of the Dry Linear Contact Between Glass Fiber-reinforced Composite Materials and Steel
}

\begin{abstract}
VIRGIL FLORESCU*, DORIN RUS, LAURENTIU RECE
Technical University of Civil Engineering, Mechanical Technologies Department, 59 Calea Plevnei, 010223 Bucharest, Romania

The thermoplastic materials studied are biphasic. They consist of a polymer mass and a short glass fiber, the percentage being between 10 and 30\%. We have shown, both analytically and graphically, the evolution of wear occurring on the steel surface in contact with glass fiber-reinforced polymers. The evolution in time of this process depends on the evolution of the friction coefficient in the process of the dry linear contact between different polymers and different types of steels. We have made a connection between the theoretical case and the experimental results. The experimental method used was the wear imprint method through which the wear depth and wear volume were determined. The wear process is complex and is accompanied byadhesion and corrosion phenomena. Anymodification of the inputparameters such as speed, temperature, load, quantity of glass fibers in the polymer lead at a certain one evolution of the wear behaviour of the composite material.
\end{abstract}

Keywords: Thermoplastic materials, friction evolution, contact temperature, wear of the steel surface, influence of steel surface hardness

There are many factors included which can influence wear of metal surface in case of permanent contact. One of most sophisticated tribosystem is between a polymer sliding in dry contact on steel. Thermoplastic composite materials with glass fibers can be used with high pressure and high temperatures. In specialist papers, values are given for the friction coefficient for different couples. The input parameters are permanently modified. Thermoplastic polymers do not allow a big deformation. It is good to use alkali-free glass fibers for a slow degradation in time and oxides can be added to maintain the high values of the elasticity module. Based on comprehensive experimental tests, a study for the evolution of wear for a certain duration, as well as for certain loads and contact temperatures was performed. The values are given for couples with dry contact. The couples are formed from reinforced composite materials on steel. The materials used are composite thermoplastic materials reinforced with glass fiber. Starting from an extended study, we have tried to come up with a graphical representation of the wear process for a dry contact between polymers reinforced with glass fibers and C120 (1.2080/ X210Cr12) steel, respectively Rp3 (1.3355/ HS6-5-2C) steel. For experimental tests, Archard's relationship was used as well as an analytical method. In our paper we have studied Timken couples and the influence of percentage of glass fiber added in polymer, in wear process. In specialist literature there is a heterogeneous approach, because different test installations, different experimental conditions and different materials which were used. Stachowiak et all [1] have studied the abrasive effect for two ball-on-flat installations and modified pin-on-disk tribometer. The ball-on-flat test yielded the most significant results. Dwyer-J oyce [2] has noticed that during contact, the wear due to contamination with solid compounds of lubricants occurs, the phenomenon closely resembling the abrasion with three bodies. Kukureka et al. [3] for the polymer they added glass, carbon or aramid and the friction coefficientwas noticed. Bartenev, Lavrentiev [4] establish that for the metal on plastic contact, the increase of sliding speed. This dependency is shown through the force; Vinogradov demonstrated. Dorin Rus and Lucian Capitanu
[5] studies tribological behaviour of dry contact polymers on steel. S. Bahadur [6] have study being carried out in a ring-block wear tester, using a dry contact. The following two aspects were observed: by adding the $\mathrm{MoS}_{2}$ filler, it has led to an increase in wear, while adding the carbon fiber filler has led to a decrease in wear. Myshkin [7] mentions that, at the surface of the composite material, the links are viscous-elastic and that the abrasive friction component is higher that the adhesive friction component. Dorin Rus et all [8, 9] study correlation between friction coefficient and steel surface wear.

\section{Experimental part \\ Materials and methods}

The base polymer is the support for the glass fibers which give the polymer resistance. The polymers were NylonplastAVE reinforced with $30 \%$ glass fibers and Lexan 3412 reinforced with $20 \%$ glass fibers. Metal samples were manufactured from two steel types: X210Cr12 (EN 10027 -1 symbolisation) or 1.2080 (SEW 260 -70 symbolisation) or (C 120 Romanian clasification) steel hardened 59 HRC and HS6-5-2C (EN 10027 -1 symbolisation) or 1.3355 (SEW 320 -69 symbolisation) or (Rp3 -Romanian clasification) steel hardened $62 \mathrm{HRC}$.

The wear depends on many parameters: loading time, slip speed and contact pressure. We studied loading and sliding speed in the infiltration of glass fiber content, to highlight the wear process.

Wear and friction are analysed from several points of view, such as speed relative to load and temperature. The two samples are: cylindrical polymer liner and flat steel sample.

A Timken contact as experimental equipment was used. Wear and friction are analysed from several points of view, such as speed relative to load and stress. The two samples are cylindrical liner and flat sample. All tests last one hour.

A Timken type couple with linear friction contact was used as experimental equipment. Thus the normal load and the contact temperature can be controlled. The friction couple is built out of a plastic cylinder which revolves at different speeds. The plastic piece rests on the polished

\footnotetext{
* email: florescuvirgil@yahoo.com
} 
surface of a steel plan disk. The cylinder has a diameter of $22.5 \mathrm{~mm}$ and a thickness of $10 \mathrm{~mm}$.

The friction couple is built out of a cylindrical liner (1) and a flat disk (2). The liner is fixed by means of a nut (3) on the driving shaft (4). The disk sample is placed in a hole made in the elastic blade (5) (Fig.1).

An electric motor (7), the shaft (4) with rotation movement using trapezoidal belt.

Figure 1 shows the functional scheme (a) friction couple (b) and its installation within the experimental equipment (c). The way in which the liner moves against the plane sample is illustrated in (Fig.1c.).
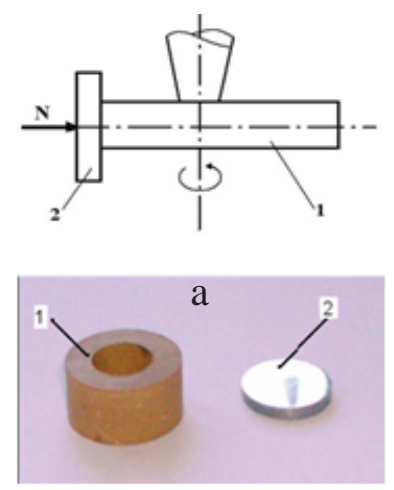

Fig.1. Functional scheme (a) the way how the liner moves against the disk, (b) friction couple, and

(c) its installation in the experimental equipment, where 1 - cylindrical liner; 2 - steel flat disk sample; 3 - nut; 4 - hole;

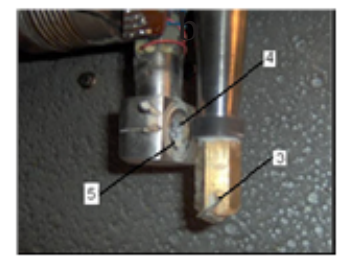
5 - knife-edge.
An electric motor (7), the shaft (4) with rotation movement using trapezoidal belt. The friction couple is built of a cylindrical liner (1) a flat disk (2). The liner is fixed by means of a nut (3) on the driving shaft (4). The disk sample is placed in a hole made in the elastic blade (5). An electric motor (7), the shaft (4) with rotation movement using trapezoidal belt transmission (6). The normal and tangential (friction) stresses are measured by means of resistive tensiometers, mounted on the elastic blade (5). The normal load to the elastic blade (5) is applied, through a calibrated spring system (8). The installation can register the friction force on an $X-Y$ recorder. The duration is controlled with a clock and the contact temperature is measured with a miniature thermocouple (9), connected to a millivoltmeter. The installation can also study the wear using other radiometers techniques. For this purpose, the installation has a tank (10) assembled on a base (11) and a tube for collecting the radioactive wear particles (12) (Fig.2).

The unidirectional testing is investigations of metal surface wear. The tests were based on Hooke's law, at normal loads of 10; 20; 30; 40 and $50 \mathrm{~N}$, loads which are adequate to some contact pressures all calculated considering the elastic contact hypothesis, meaning: 16.3; 23.5; $28.2 ; 32.6$ and $36.4 \mathrm{MPa}$.

\section{Analytical method}

The functioning under load of the Timken type and in presence a relative sliding movement of the bushing made of glass fiber reinforced plastic on steel sample, highlights the occurrence of a imprint on the plane metal surface. The imprint is graphically represented in (Fig.3).

C

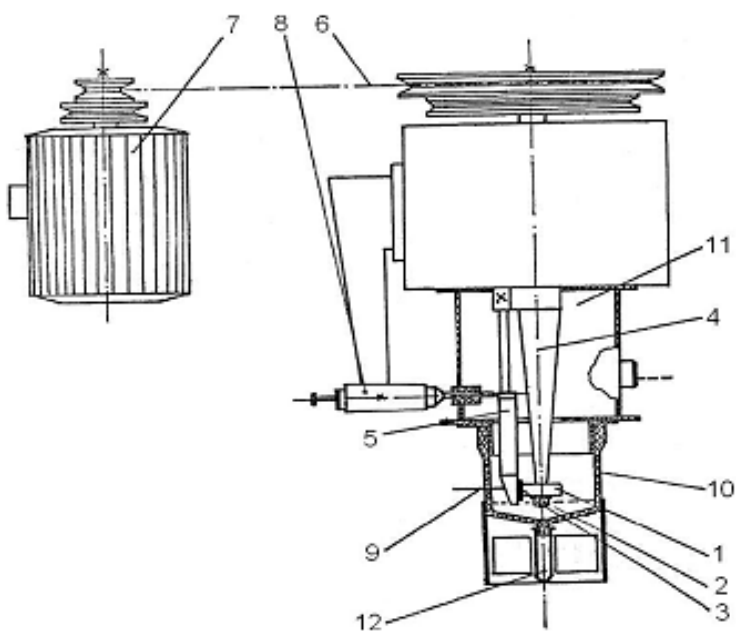

Fig. 2. The scheme of experimental equipment with linear contact friction couple, Timken type

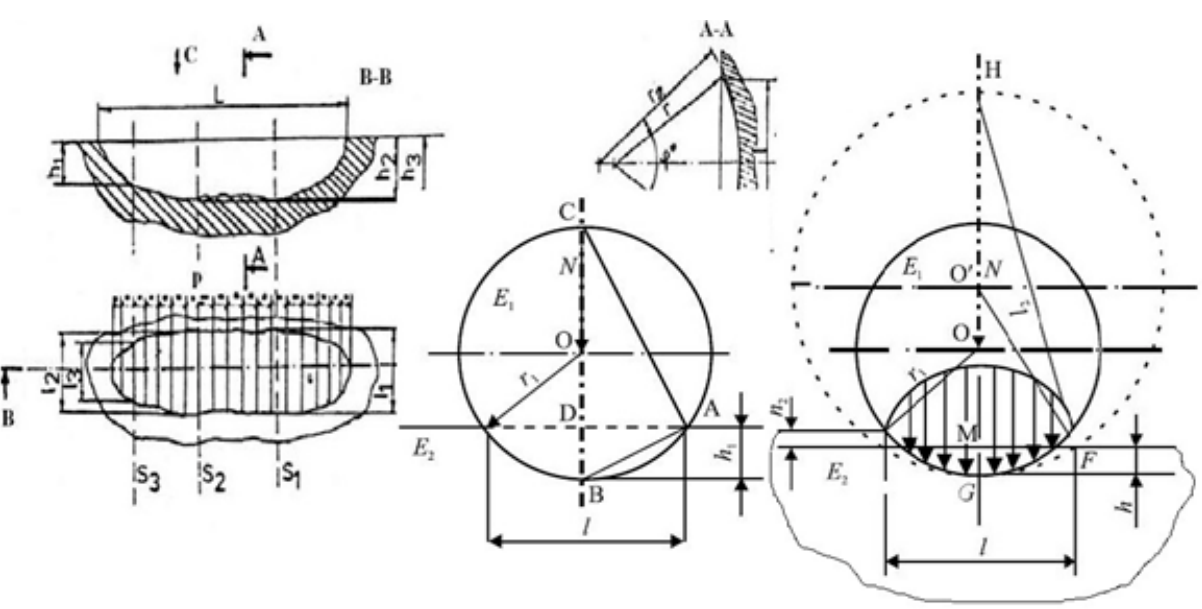

Fig. 3. The imprint scheme for Timken friction couple 
knowing Coulomb's $F_{f}$ directly:

$$
\begin{aligned}
& F_{f}=a+b N \\
& F_{f}=a+b N^{n} \\
& \mu=\tau_{f} / p_{c} \\
& \mu=3 \tau_{f} / H B
\end{aligned}
$$

$l$ for the width of the wear imprint, from $\triangle A B C$ it is:

$$
\left(2 r_{1}-h_{1}\right) h_{1}=l^{2} / 4
$$

equivalent curvature radius:

$$
\begin{gathered}
1 / r=1 / r_{1}-1 / r_{2}=\left(r_{2}-r_{1}\right) / r_{1} r_{2} \\
l=4\left[2 N r\left(1-v^{2}\right) / \pi E L\right]^{1 / 2}
\end{gathered}
$$

Poisson value ratio :

$$
h_{2}=0.527 N\left(E_{1}+E_{2}\right) / L E_{1} E_{2}
$$

depth wear imprint:

$$
h=\left(l^{2} / 8 r_{1}\right)-0.527 N\left(E_{1}+E_{2}\right) / L E_{1} E_{2}
$$

the area of the lateral surface of a sector is:

$$
\begin{gathered}
S_{i}=r^{2} \phi^{3} / 12 \\
S_{i}=l^{3}\left(r_{2}-r_{1}\right) / 12 r_{1} r_{2}=2 l m_{2} / 3
\end{gathered}
$$

lateral transversal surface of cylindrical sector:

$$
S_{i}=0.35 l\left(E_{1}+E_{2}\right) N l / E_{1} E_{2} L
$$

volume of worn metal material will be:

$$
\begin{gathered}
V_{u}=\sum_{i=1}^{n}\left(S_{i} q_{i}\right)=0.351\left(E_{1}+E_{2}\right) N l_{m} / E_{1} E_{2} \\
\mu=A \ln N+B
\end{gathered}
$$

contact temperature:

$$
T=\sum_{i=0}^{2} a_{i} \exp [(\mu-B) i / A]
$$

\section{Results and discussions}

Tests were performed for more sliding speeds 27.85, $37.13,46.41,55.70$ and $111.4 \mathrm{~cm} / \mathrm{s}$ (Table 1). Regression functions were calculated for each coupler.

The function attached to the wear volume [Vu] is in relation with the load.

This phenomenon is very complex and evolves from abrasive to adhesive wear and to corrosion, simultaneously with transfer of thermoplastic material on metal surface.

The closed loop between the input and output parameters, taking into consideration the modification of the initial parameters especially the modification of the metal surface after wear (Fig.4).

For experimental testing we used the Archard relationship, in conditions of dry slip friction and adhesion wear. All tests were limited to an hour for couple shown in (Table 1) and graphics were plotted for each test (figs. 510).

It is noticed that with the increase of the load there appears a nonlinear variation of the temperature and the volume of wear (Fig.5).

Figure 6 shows the evolution of the same parameters but for a relative double speed. Note the change of the temperature curve related to the load.

Figure 7 shows that for high speeds the temperature and the volume of wear increases slowly in relation to the load. By analyzing the results presented in figures 5 to 7 , the theory of the existence of a critical speed for the behavior of the wearer is confirmed.

A similar analysis is made for the other steel brand. As shown in figure 8, similar values are obtained for the wear volume for contact with C120 but at a lower speed.

\begin{tabular}{|c|l|l|c|}
\hline \multicolumn{1}{|c|}{ Timken couple } & $\begin{array}{c}\text { Correlation } \\
\text { factor }\end{array}$ & Regression & $\begin{array}{c}\text { Speed } \\
(\mathrm{cm} / \mathrm{s})\end{array}$ \\
\hline $\begin{array}{c}\text { NYLONPLAST AVE with } 30 \% \text { glass fiber on } \\
\text { C120 steel }\end{array}$ & $\mathrm{R}^{2}=0.9985$ & $\mathrm{t}=0.185 \mathrm{x}^{2}-1.55 \mathrm{x}+147$ & 55.70 \\
\hline $\begin{array}{c}\text { NYLONPLAST AVE with 30\% glass fiber on } \\
\text { C120 steel }\end{array}$ & $\mathrm{R}^{2}=0.9921$ & $\mathrm{t}=0.06 \mathrm{x}^{2}+5.9 \mathrm{x}+179$ & 111.4 \\
\hline $\begin{array}{c}\text { NYLONPLAST AVE with 30\% glass fiber on } \\
\text { C120 steel }\end{array}$ & $\mathrm{R}^{2}=0.9993$ & $\mathrm{t}=0.16 \mathrm{x}^{2}+9.2 \mathrm{x}+159$ & 153.57 \\
\hline $\begin{array}{c}\text { NYLONPLAST AVE with } 30 \% \text { glass fiber on } \mathrm{Rp} \\
3 \text { steel }\end{array}$ & $\mathrm{R}^{2}=0.9995$ & $\mathrm{t}=0.2667 \mathrm{x}^{2}+20.933 \mathrm{x}$ & 37.13 \\
\hline $\begin{array}{c}\text { NYLONPLAST AVE with } 30 \% \text { glass fiber on } \mathrm{Rp} \\
3 \text { steel }\end{array}$ & $\mathrm{R}^{2}=0.9956$ & $\mathrm{t}=0.28 \mathrm{x}^{2}-4.6 \mathrm{x}+136$ & 46.41 \\
\hline LEXAN 3412 with 20\% glass fiber on C120 steel & $\mathrm{R}^{2}=0.9977$ & $\mathrm{t}=0.08 \mathrm{x}^{2}+7.1 \mathrm{x}+100$ & 27.85 \\
\hline
\end{tabular}

Table 1

TESTSRESULTS ON CONTACT

TEMPERATURE [T], NORMAL LOAD [N] AND $\mathrm{SPEED}[\mathrm{cm} / / \mathrm{s}]$

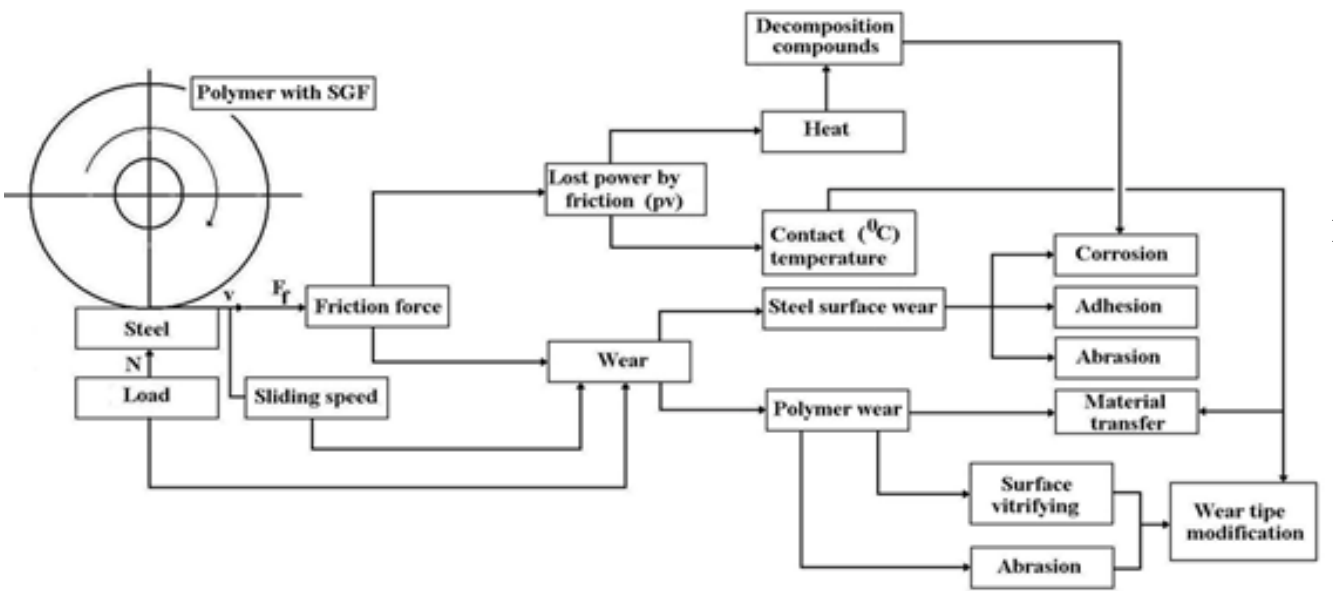

Fig. 4. The complex evolution process of friction at wear in linear contact polymer with short glass fiber on steel 

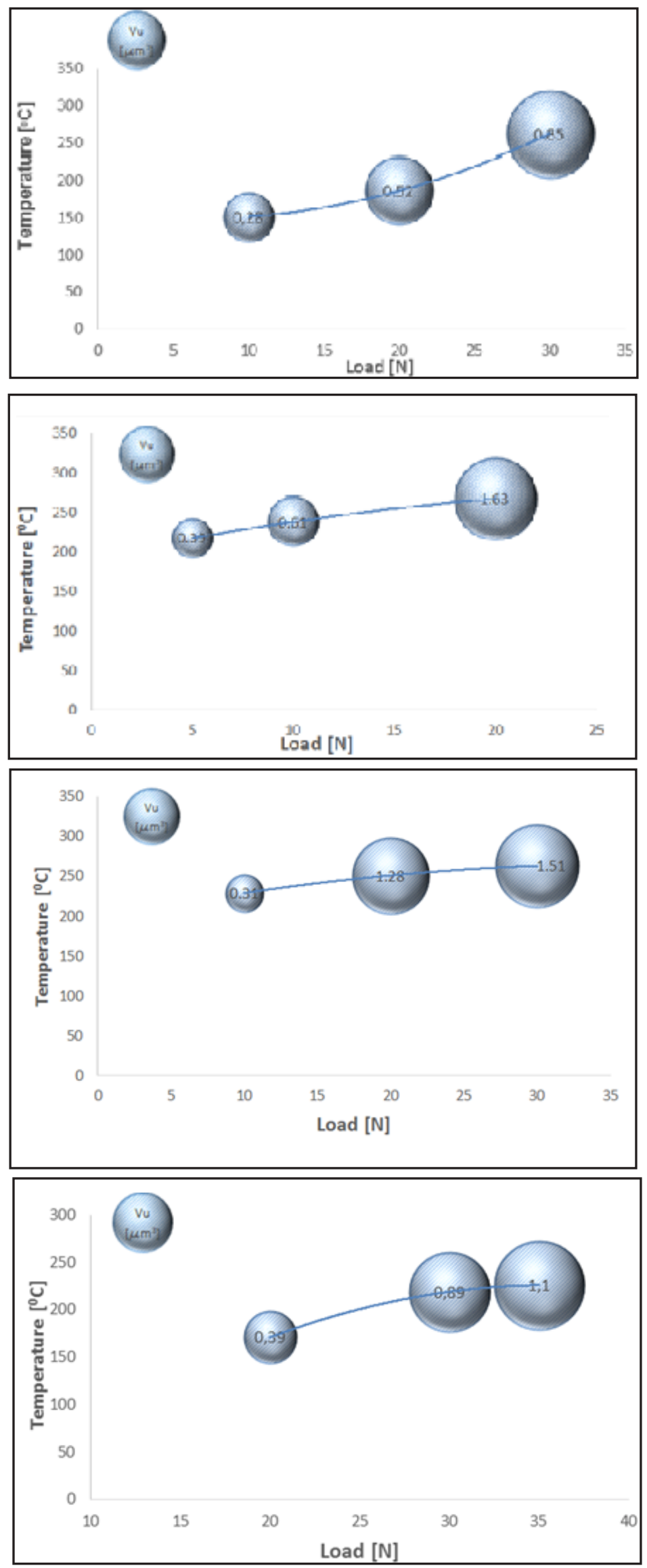

Fig. 5. Wear volume [Vu] evolution for NYLONPLAST AVE with $30 \%$ glass fiber on C120 steel at sliding speed $55.70 \mathrm{~cm} / \mathrm{s}$

Fig. 6. Wear volume [Vu] evolution for NYLONPLAST AVE with $30 \%$ glass fiber on C120 steel at sliding speed $111.4 \mathrm{~cm} / \mathrm{s}$

Fig. 7. Wear volume [Vu] evolution for NYLONPLAST AVE with $30 \%$ glass fiber on C120 steel at sliding speed $153.57 \mathrm{~cm} / \mathrm{s}$

Fig. 8. Wear volume [Vu] evolution for NYLONPLAST AVE with $30 \%$ glass fiber on Rp 3 steel at sliding speed $37.13 \mathrm{~cm} / \mathrm{s}$
Similar to the $\mathrm{C} 120$ friction couple, Fig. 9 shows that for Rp3 there is a relative speed and a load at which the wear volume decreases compared to the recordings in figure8.

Figure 10 confirms that the wear at low speeds is significant and also leads to the existence of a critical speed for this case.
The correspondence between wear volume and load is directly related to the maximum temperature during the process. The wear volume provides with important information on the specific evolution of the tribosystem over time. 

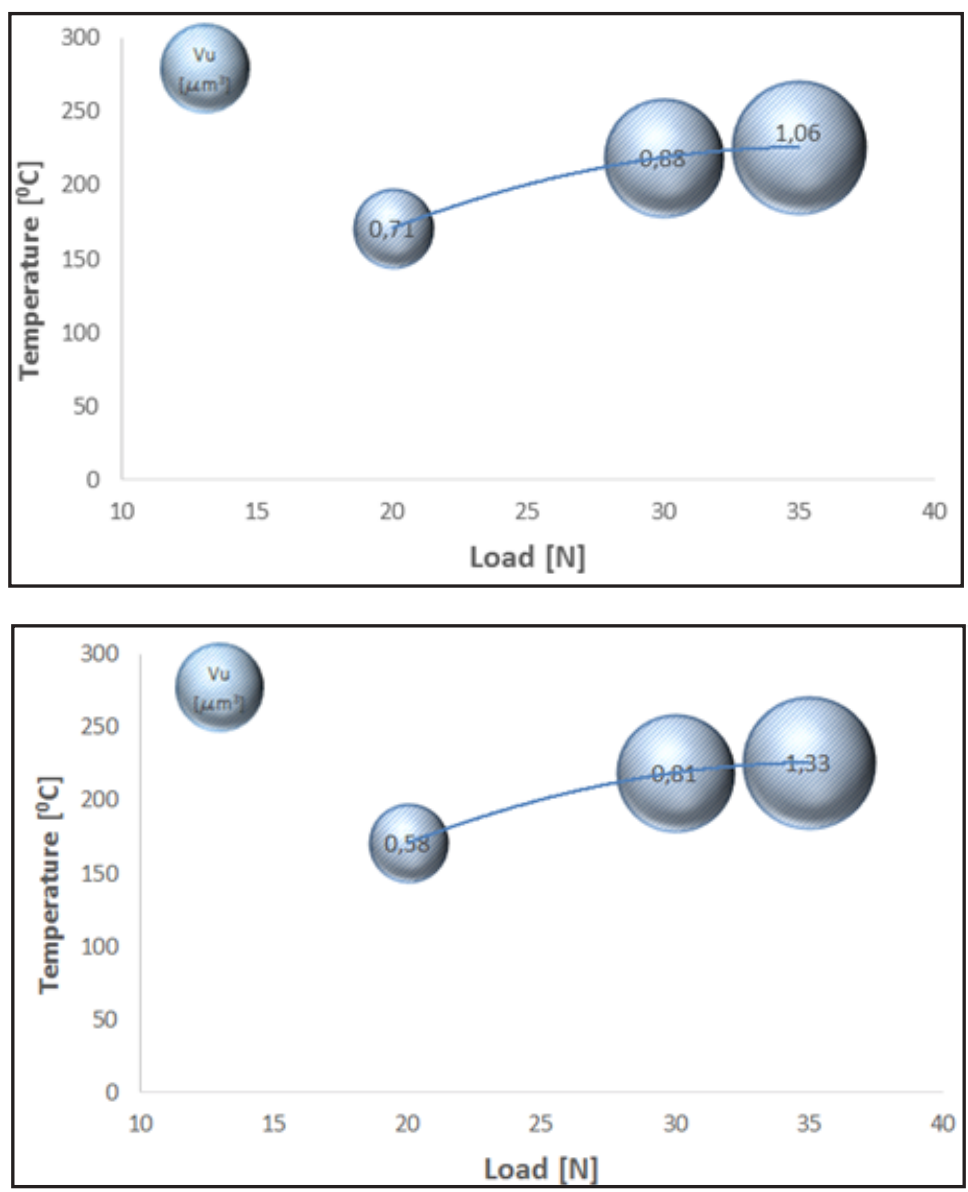

The linear contact was chosen to minimize the running in period. It is not by accident that steels have been chosen, which are useful for the manufacture of tools. The study on wear behaviour of this friction couple finds its usefulness at the stage of processing materials.

\section{Conclusions}

The friction couples, in short glass fiber reinforced thermoplastic material / steel, were influenced by the input parameters of the tribosystem (normal load, contact pressure, relative sliding speed).

From the information presented above we can draw some conclusions:

The wear phenomena make sense and significant influence in friction couple behaviour after the first working hour.

The linear dry contact between the composite material and steel is highly complex. By changing a single input parameter, all output parameters of the systems will change. The wear of steels in contact with reinforced polymer is significant. The steels tested are those designed to manufacture the active parts of the reinforced polymer processing machines. The set of parameters of load, speed and temperature can be considered as a unitary factor in the analysis of such a couple of material. The challenge is to optimize it. The results presented in the paper consider that they are useful for inputting technological processes of manufacturing and equipment maintenance.
Fig. 9. Wear volume [Vu] evolution for NYLONPLAST AVE with $30 \%$ glass fiber on Rp 3 steel at sliding speed $46.41 \mathrm{~cm} / \mathrm{s}$

Fig. 10. Wear volume [Vu] evolution for LEXAN 3412 with $20 \%$ glass fiber on C120 steel at sliding speed $27.85 \mathrm{~cm} / \mathrm{s}$
The wear volume for the friction couple between composite material and for the C 120 steel samples is higher than the one obtained on the surface of the Rp3 steel samples. This is due to the differences in hardness between the two types of steel. The phenomen is valid for themperature evolutions too.

Acknowledgements:The authors thank to the Technical University of Civil Engineering Bucharest, logistic support to achieve researche.

\section{References}

1. STACHOWIAK, B., STACHOWIAK, G.W., Wear, 249, 2001, p.201

2. DAVYER-J OICE, R.S., SAYLES, R.S., IOANNIDES, E., Wear, 175, 1994, p. 133

3. KUKUREKA, S.N., HOOKE, S.N., RAO, M., LIAO, P., CHEN, Y.K., Tribol. Intl., 32, 1999, p. 107

4. BARTENEV, G.M., LAVRENTIEV, V.V., KONSTANTINOVA, N.A., Wear, 18, 6, 1971, p.439

5. RUS, D., CAPITANU, L., J. Mech. Energy Eng., 5, 2015, p.554

6. BAHADUR, S., Wear 245, 2000, p.92.

7. MYSHKIN, N.K., PETROKOVETS, M.I., KOVALEV, A.V., Tribol. Intl., 38 (11-12), 2005, p.910

8. RUS, D., CAPITANU, L., BADITA, L.L., Friction, 2(1), 2014, p.47

9. FLORESCU, V., RUS, D., CAPITANU, L., Appl. Mech. Mater., 1061, 2015, p. 626

$\overline{\text { Manuscript received: } 28.06 .2019}$ 